\title{
Ideology at Work: Reconsidering ideology, the labour process and workplace resistance.
}

\begin{abstract}
Purpose - The purpose of this paper is to consider existing debates within the sociology of work, particularly the re-emergence of Labour Process Theory (LPT) and the 'collective worker', in relation to resistance at work. Through presentation of primary data and a dialectical discussion about the nature of ideology, the paper offers alternative interpretations on long-standing debates and raises questions about the efficacy of workplace resistance.
\end{abstract}

Design - The design of this methodology is an ethnographic study of a call centre in the North-East of England, a covert participant observation at 'Call Direct' supplemented by semi-structured interviews with call centre employees.

Findings - The findings in this paper suggest that resistance in the call centre mirrors forms of resistance outlined elsewhere in both the call centre literature and classical workplace studies from the industrial era. However, in presenting an alternative interpretation of ideology, as working at the level of action rather than thought, the paper reinterprets the data and characterises workplace resistance as lacking the political potential for change often emphasised in LPT and other workplace studies.

Originality - The original contribution of this paper is in applying an alternative interpretation of ideology to a long-standing debate. In asking sociology of work scholars to consider the 'reversal of ideology', it presents an alternative perspective on resistance in the workplace and raises questions about the efficacy of workplace disobedience.

\section{KEY WORDS}

Resistance, labour process theory, ideology, work, call centres, collective worker

The workplace, despite increasingly moving to the margins of sociology, remains uniquely positioned to connect macro, mezzo and micro level issues and integrate social theory with empirical data (Strangleman 2005). This paper integrates 
empirical data with theoretical discourse on the nature of ideology whilst offering critical analysis of a number of existing theoretical frameworks. One of the most fruitful areas of debate within the sociology of work has proven to be employee resistance (Blauner 1964; Braverman 1974; Beynon 1975; Ackroyd \& Thompson 1999; Taylor \& Bain 1999; Mulholland 2004). Braverman's (1974) Marxist analysis of the industrial workplace and exploitation at the point of production suggested that Labour Process Theory (LPT) could explain employee resistance at work and also point the way towards a radical political agenda to overhaul capitalist social relations that alienate the worker. Critics rejected Braverman's thesis for ignoring the 'subject at work' (Knights 1990), focusing on objective conditions without explaining the role agency or subjectivity plays in the work process. These critics repositioned the workplace in light of the individualisation of subjects seeking a stable self-identity and self-disciplining their behaviour at work (WIllmott 1990, see Tinker 2002 for an overview). Resistance became less institutionalised and more individualised as workers chose to accept the conditions of their employment in order to stabilise a sense of self.

The concept of the 'collective worker' (Martinez Lucio \& Stewart 1997; Mulholland 2004) reintroduces the labour process into workplace analysis; by informally working together to resist the iniquities of the labour process, employees collectively become conscious of the conditions of their oppression and exploitation at work. This realisation, the falling veil of false consciousness (Eagleton 2007), opens up avenues for future resistance in a more formal collective manner that will seek to overcome the exploitative work process and management practice engendered under capitalist social relations (see Mulholland 2004). This paper asks a simple question: what implications arise for workplace resistance if we consider empirical evidence according to a different theoretical understanding of ideology? Drawing on data from an ethnographic study of the service economy in the North East of England, this paper will present evidence that many may suggest supports the 'collective worker' thesis. The aim of this paper is to interpret the data according to Slavoj Zizek's 'reversal of ideology' (1989; also Fisher 2009). In taking this theoretical approach, the conclusions and implications 
of the findings presented here suggest something other than a potential for formal collective resistance.

\section{Labour Process Theory and 'the subject at work'}

Labour Process Theory (LPT) largely focused on the dialectic between control and resistance within an organisation, at the point of production (Thompson and Smith 2009). Most literature agrees that LPT stems from Braverman's (1974) Labor Monopoly and Capital. Braverman (1974) rejected the prevailing wisdom that work was becoming more skilled and alienation subsiding. By returning to analysis of the labour process, breaking it down into its constituent parts, Braverman suggested that work was de-skilling, that Taylorist 'scientific management' degraded the work undertaken by employees and made labour power a commodity increasingly cheapened by the capitalist mode of production (1974: 57$)$. The more control exerted over the labour process by management, the more resistance emerged from disgruntled and alienated workers. Employees become acutely aware of the diminution of the skill required in the labour process and resisted scientific management through the trade union movement. Resistance, in this context, was clear. The labour process was alienating and oppressive therefore collectivism was required in order to liberate employees from the desultory conditions of their employment. In this context, the trade union movement makes sense; collective action, aimed at reforming and improving the material conditions of working life was a vital bulwark against the iniquities of capitalist profitmaking.

For Braverman, labour represents the revolutionary potential of class. Analysis of the labour process reveals labour as a 'class-in-itself', collectively oppressed by capital. This recognition of labour as a 'class-in-itself' will, through the revolutionary potential of the working classes, result in labour becoming a 'classfor-itself', overthrowing capitalist social relations and liberating the worker from oppression. Commensurate with the thinking of post-war cultural Marxists such as E.P. Thompson and Raymond Williams (Dworkin 1997; also Winlow et al 2015), belief that the working class maintains a revolutionary spirit waiting to be unlocked underpins this analysis. Braverman posits a political sociology, analysis 
of the labour process is essential in consciousness-raising. This rests on a specific interpretation of ideology which, as noted above, is the subject of critique and discussion in this paper.

Burawoy (1979) split the control-resistance dualism by suggesting that employees consented to their own oppression. Employee consent is crucial to the realisation of surplus value and the continuity of capitalism as without workers' consent, surplus value cannot be secured. The conceptual differentiation between labour and labour power is crucial; just because I agree to sell my labour power doesn't mean my labour is realised. Only in realising the employee serves their own interests by consenting to partake in the labour process does the capitalist realise surplus value through the production process. This rethinking of the labour process extends to the autonomy of the labour process in specific contexts. Edwards (1990) and Thompson (1990) separate the labour process at the organisational mezzo level from the wider macro level context, thus separating capital from labour; in certain institutions or workplaces, employees may refuse to engage in the labour process, e.g. resist, but overall, the consent of the employee is required for surplus value to be recognised. This bifurcation serves to leave capitalism intact whilst contemplating the conditions in individual settings and sites of resistance. This begins the shift away from the labour process in general as a site for radical analysis and politics and towards a situation where oppressive conditions in a particular locale are dismissed as site-specific and not indicative of the wider labour process or the nature of capitalism per se (Spencer 2000).

LPT became the subject of vigorous critique from a post-structuralist position (Knights 1990; Willmott 1990). A 'Foucauldian' turn in LPT attempted to resolve the perceived flaw in Braverman's thesis; the 'missing subject' in the labour process. In focusing on the objective conditions of the labour process, Braverman appeared to neglect the subjective experience of the employee. Spencer (2000) argues that Braverman did not neglect the subject but instead regarded alienation as objective rather than subjective. If Marx's (and Braverman's) ontological position stemmed from a historical materialism asserting man's labouring capacity as essential, the human as a productive being, then separation from the means of 
production under capitalism was inherently alienating, regardless of the subjective state of mind of the individual worker.

Nevertheless, following the 'cultural turn' (Thompson \& Smith 2009), LPT emphasised the 'subject at work'. Identity, rather than labour, becomes the focus of analysis (Knights \& Willmott 1989). The process of individualisation taking place in an increasingly fragmented labour market leads to a fundamental insecurity and anxiety at the heart of the subject. The individual seeks assurance and selfvalidation and this carries over into the workplace. We secure our self-identity by self-discipline in the workplace, submitting to the control and authority of management (Spencer 2000). Workers subjugate themselves to the work process, voluntarily 'buying into' the system, reproducing relations of power and control between managers and employees (Thompson \& Smith 2009; Knights \& Willmott 1989). McCabe (2007) attempts to integrate LPT with subjectivity by suggesting resistance is relational; in some instances the exercise of power has an individualising effect, for example, the threat of redundancy, but in other situations collective resistance emerged. Again, using a Foucauldian framework of power, subjectivity is framed by power relations and characterised by reflexivity; the subject as a reflexive agent responding to workplace dynamics becomes the focus rather than structural factors or the nature of capitalist social relations (see O’Doherty \& Willmott 2001).

Firstly, enough evidence exists to refute the suggestion that employees meekly buy into the system (Bain \& Taylor 2000; Mulholland 2004; Lloyd 2013). Resistance, disobedience and misbehaviour have continued in the workplace with remarkable similarity to forms of resistance and disobedience demonstrated during industrial modernity (Ackroyd \& Thompson 1999). Secondly, the insecurity around selfidentity has, according to other studies (see Lloyd 2012, Winlow \& Hall 2006), not touched the workplace. During industrial modernity, the workplace was a site for the construction of stable identity and the grounding markers of a symbolic order (Lacan 2007; Zizek 2000) that anchored the subjective identity of the worker. Some writers would suggest that the workplace no longer holds that position; 
whilst the value of work has not diminished, the project of the self, for many is constructed outside of the workplace (see Lloyd 2012; 2013, Winlow \& Hall 2013).

Finally, Foucault's work has been heavily criticised on a number of fronts: Baudrillard (2007) rejects Foucault's concept of power, suggesting that it does not exist. Baudrillard suggests that nobody actually exercises power and nobody actually challenges it; those in charge recognise that power does not actually exist in reality whilst those who think power exists are those who become subject to the will of others. In the workplace, managers hold power only in the sense that the employees fail to recognise the fact that, ultimately, managers are powerless. Secondly, Foucault has been criticised as a neoliberal apologist (Zamora 2015) which reflects the movement away from LPT as a potential site of revolutionary politics; Foucault and his followers concentrate on micro-sites, the cultural sphere and the individual subject whilst leaving the material and ideological edifice of capitalism free from critique and able to continue reproducing itself unchallenged. For example, Thompson (2003) concludes his critique on call centre surveillance systems by suggesting that conclusions should take into account specific organisational context and not how a whole societal or workplace regime should be characterised. Without connecting the macro with the mezzo and micro, Thompson misses the opportunity to reflect on the nature of capitalism in contemporary society and the potential harm it inflicts on the workplace.

The shift in focus away from class and towards identity, constitutive of the 'cultural turn' of postmodernism had implications for the sociology of the workplace. LPT was inextricably bound to class analysis and industrial sociology; with the onset of deindustrialisation and the decline in class discourse in the public sphere, LPT largely diminished from view (Spencer 2000). Some have returned to LPT through the concept of the 'collective worker' in order to reposition the workplace as a site for potential collective action (Martinez Lucio \& Stewart 1997). Martinez Lucio and Stewart's (1997) return to Marx's notion of the 'collective worker' has resonated with some call centre research (see Mulholland 2004). Their central claim is that the individualisation process (Beck \& Beck-Gernsheim 2002) creates a false binary between collectivism and individualism. If $H R$ and 
management strategies promote the individual, it is at the expense of or facilitates a decline in collective struggles and identification. However, if one posits the 'collective worker' in the labour process, Lucio Martinez and Stewart argue that this transcends the false dualism between individualism and collectivism; surplus value is never created by a single individual acting autonomously. Individual workers carrying out tasks as part of a collective labour process create surplus value for the employer. This reorientation in focus, away from the individual subject and towards the labour process, provides a space for a more meaningful discussion of the political potential of workers in increasingly individualised workplaces. Lucio Martinez and Stewart's (1997) final point emphasises that identifying collectivism in the guise of organised collectivist institutions such as trade unions is an act of reductionism failing to account for new collective approaches that renew the workplace as a site of struggle.

Research on organisational cultures is broad (Brown 1998, Parker and Bradley 2000, Bond 2004, Burnett and Huisman 2010). The call centre is not a uniform institution with one organisational culture and management practice (Glucksmann 2004) but does represent a specific form of organisational culture. Within the call centre literature, resistance has been a key feature (Bain \& Taylor 2000; Deery et al 2002; Fleming \& Sturdy 2011; Brophy 2010; also Lloyd 2016). Analysis of the labour process within the call centre has yielded a number of studies (Bain \& Taylor 2000; Mulholland 2004; McFadden 2015). For example, McFadden (2015) considers the role of 'body work' in the reproduction of capitalist social relations and capital accumulation through the labour process. Others have attempted to operationalise the concept of the collective worker to reframe analysis of disobedience, misbehaviour and resistance at work (Taylor \& Bain 1999; Mulholland 2004).

Mulholland (2004) posits the collective worker as the conceptual tool to explain evidence from an Irish call centre. Seemingly individualised practices of slammin', scammin', smokin' and leavin' routinely provided personal satisfaction for the employee but were embedded in an informal collective approach to acts of disobedience and resistance; employees passed on tips and feigned ignorance or 
indifference at management attempts to interrogate teams over acts of resistance. Mulholland suggests that employees demonstrate solidarity in a tacit and covert manner, defying management in the process. Resistance and disobedience in the workplace needs to be framed within the context of the social relations of production (ibid); sabotage, work avoidance, absenteeism and turnover are expressions of workplace antagonism and, in rejecting the individualisation of the worker thesis, suggests that analysis of the labour process and employee engagement uncovers tacit and less visible collective responses that highlight the contradictory and conflict-ridden nature of employment relations. This collective response raises awareness of the character of call centre exploitation that fosters the potential for more organised collective responses somewhere in the future. However, despite learning various responses through collective means, much of the resistance is enacted individually and in some cases, as this paper will highlight, individual responses will negatively impact on other colleagues. This relationship between individual responses and collective learning raises interesting questions about the nature of resistance at work. While Mulholland presents an excellent case study highlighting the importance of placing the individual subject within the labour process and locating avenues of collective potential, a thoroughgoing reinterpretation of the nature of ideology may dampen this analysis.

\section{Methodology}

The data presented below comes from an ongoing ethnographic study of the service sector in Middlesbrough, in the North East of England. Specifically, this paper is drawn from a six-month covert ethnography of a call centre anonymised here and elsewhere as Call Direct. The author was employed as a Customer Service Representative (CSR) for six months by Call Direct, an outsource call centre providing facilities and staff to manage overflow calls for Internet Plus, a broadband supplier. This data is supplemented with semi-structured interviews with Call Direct employees and other call centre employees. In total, 30 informal discussions and 15 recorded interviews took place. All informants were characterised as either British White or British Asian, reflecting local demographics, split almost 50-50 across gender lines (reflecting the gender divide at Call Direct but not representative of the industry as a whole), aged 
predominantly between 18 and 30, and corresponding to what would traditionally have been called 'working class' but perhaps most appropriately fits 'precariat' or 'emerging service workers' in Savage et al's (2015) new class configuration.

The obvious methodological challenge to this research is the ethical implications of covert observation (Spicker 2011, van Amstel 2013). Space prevents a detailed discussion of the strengths and weaknesses of covert ethnography but it is sufficient to say that every effort has been made to protect the anonymity of coworkers, informants and the employer thus minimising any risk of harm, particularly to informants discussing their feelings about employers. Call Direct and Internet Plus are pseudonyms, as are all of the names used in this paper and elsewhere. There are ethical considerations with any research method and criticism of ethnography on the grounds of ethics reflects a growing institutional concern with managing risk as well as the cost associated with researchers embedded in the field for long periods of time. The issue of informed consent is important and the British Sociological Association's Statement of Ethical Practice states that informed consent should be sought 'as far as possible'; in this case it was felt that seeking informed consent from Call Direct and its employees prior to undertaking the research would have prevented access to the research setting. Questions relating to reliability and validity (Bryman 2012) can be issued to any method, not solely covert observation, and questions regarding the risk of autoethnography (see Duncan 2004) are negated through the semi-structured interviews that were designed to challenge or confirm the initial findings from the fieldwork.

The aim of the project was to investigate the daily experience of call centre work in an area built on the 'traditional' working class work of iron and steel manufacturing and petrochemical production but increasingly finding itself reliant on service sector work. In considering the obstacles to gaining entry to the research setting, it became apparent that covert observation was the only option. Ethical clearance was sought and obtained from my host institution before undertaking employment at Call Direct (see Van Amstel 2013). This should be the only question a researcher faces when preparing their fieldwork - is it the best 
method in terms of meeting the aims and objectives of the project? Whilst many sociologists oppose covert methods, in order to meet the aims and objectives of this project, the method chosen was the only suitable method.

\title{
Resistance at Call Direct
}

At Call Direct, several forms of disobedience were observed and employees outlined their reasons behind participation in such activities as 'taking back time', 'ready-release' and closing customer accounts. Resistance existed outside of the automated work process; new employees spent their first two days of training learning about the company and its values. Identifying with the owner and her aims and ambition for the company was seen to be important. Management literature suggests that this form of 'hearts and minds' training facilitates employee identification with the company, investing themselves in the workplace and therefore less likely to resist what otherwise might be regarded as oppressive working conditions (van den Broek 2004). Brand values such as 'passion for service' were painted on the walls to remind employees of their 'mission'. When asked about identifying with the brand values, respondents were cynical and mocking. Darren, a 31 year old team leader, replied,

\begin{abstract}
"Oh, not one bit. I'd be surprised if anyone does. Like I said earlier, there's perceptions and how the company portrays itself to impress the clients, the job centres, job fairs, and then there's us who've worked there for a while. Speaking for myself, I don't know about you, when you join, it's painted as a really, really good place to work and you get bitten by the bug when you first start and you think it's not actually a bad place because they try to embellish the fact, they try to make, they are good at taking ten strangers and forming a team over two or three weeks of training, but when you hit reality of the floor and you've got targets and that, people then go to work to serve themselves and not the company. The brand values go out of the window."
\end{abstract}

More succinctly, Tracy, a former Call Direct manager responsible for creating shift patterns for CSRs based on client demands, responded by saying, 
"No! It makes you want to puke in a bucket."

The hearts and minds approach at Call Direct was clearly rejected, not only from CSRs answering calls, but many of the team leaders and managers. There is no false consciousness here, they know how bad it is and can see the instrumentality behind trying to embed the values into employees. They reject the brand values and maintain a cynical distance from it; I work there but I don't buy into the corporate line. The 'knowing subject' gets one over on her employer because they have failed to indoctrinate her. However, as Slavoj Zizek (1989; 2000; 2010) suggests, this is how ideology works, as a fetishistic disavowal whereby the subject knows what is happening but continues acting as if they do not know, not a veil of false consciousness that, once it slips and the employee recognises their exploitation will inevitably lead to resistance. Capitalism affords a measure of resistance, a space for employees to feel like they are resisting something whilst simultaneously continuing to reproduce the material and social relations necessary for capitalism to continue (Zizek 1989). While the employee resists inculcation into the Call Direct brand, they continue answering calls set by an automated work process, dealing with customer enquiries and creating surplus value for the company. Nothing changes but the subject feels as though they have subjectively resisted; I did what you asked but you didn't win my loyalty.

\section{Taking Back Time}

In terms of the labour process, experienced CSRs would discretely pass on tips to new starters on how to 'beat' the system. It was certainly the case during the fieldwork that befriending particular individuals facilitated learning these techniques. However, interviewing Call Direct employees indicated that this was a widespread practice, understood across teams and departments. While Call Direct was not quite an 'electronic panoptican', call centre managers placed significant emphasis on each worker's statistics and figures produced by the electronic governance system. Throughout this study it became apparent that, while the system records details for every CSR, the length of time they were logged on, the number of calls taken, and call handling times, without the manager or team 
leader scrutinising this data, the CSR would not be expected to justify their output. However, many CSRs had seen managers force others to work late as they had not completed $71 / 2$ hours the previous day or CSRs being maligned in front of co-workers for poor performance or bad statistics. This led many to believe that, while team leaders may not be watching, someone was and it was better to stay ahead of the system.

One of the floor-walkers, Chrissie, passed on a tip to beat the system. Floorwalkers are experienced CSRs who shadow new teams for their first fortnight, helping out with system knowledge and company policies. Chrissie had worked at Call Direct for over 2 years and was happy to impart her knowledge to the new starters. The idea behind 'taking back time' was to extend break times without working past the end of the shift or, if possible, working less than the required $71 / 2$ hours. By logging onto the system 2 or 3 minutes before the shift starts and then ensuring the first two breaks did not overrun, a CSR could usually extend their final break by 2 or 3 minutes and still finish on time. This was beneficial on morning shifts when calls were not streamed through until exactly 7am; providing a team leader was not watching, a CSR could sign on early knowing that no call would come until at least 7am. Chrissie's rationale was simple; 'don't give them any more of your time than you have to; they won't give it back'.

As measurement becomes more refined, our conception of time is transformed. The 'tyranny of the clock' (Woodcock 1944) has been an important element in analysing the commodification of time since the Industrial Revolution. It stresses the present and we become increasingly aware of the time it takes to complete a task rather than the task itself. Watching the clock takes precedence over using time constructively or in the pursuit of meaningful ends. As a result, in situations where we measure time to an unprecedented degree, any attempt to reverse this process becomes important. In the call centre, the measurement of time reaches an unusual level of refinement. Minutes and seconds take on huge significance given that CSRs spend $7 \frac{1}{2}$ hours under an electronic microscope which monitors call times, idle times, wrap up times, break times, and toilet breaks. Measuring time becomes more significant than call quality, keeping call handling times low is 
often prized above customer satisfaction. This obviously has implications for a business model failing to ensure quality service. Training at Call Direct emphasised both call quality and quantity, reflecting a dichotomy oft-recited in the academic literature (Taylor \& Bain 1999; Robinson \& Morley 2006). However, management pressure on employees overwhelmingly focused on wrapping up calls and ensuring call queues were reduced, indicating that, when pushed, quantity mattered more than quality.

For CSRs, time becomes boring, waiting for the clock to move round to break time or home time, therefore the idea of taking back precious seconds and minutes becomes a challenge. Every second is accounted for, categorised, and scrutinised to a degree that prompts the CSR to push back; I may not be able to change the work process or the conditions on the call centre floor but I can potentially affect the amount of time I give to this process. Small victories take on huge significance. 'Taking back time' comfortably fits within the control thesis as employees assert their subjective desire to resist an overly controlling system of scientific management. Automated work processes that reduce autonomy provoke a reaction from the individual subject, pushing back and reclaiming time for oneself. This could also correspond to the 'collective worker' thesis as it clearly demonstrates an informal network of resistance amongst co-workers who share advice and techniques on resisting the labour process in the call centre although it remains an individualised act motivated by personal gain.

\section{Call Avoidance}

Call avoidance, or 'ready-release', was the most common form of resistance to an automated work process. Calls are automatically directed to the CSR waiting longest in the call queue; by pressing 'release' to come out of the queue then immediately pressing 'ready', the CSR goes to the back of the queue, ensuring a longer wait for a call. It was a way to avoid taking a call at the end of a shift and risk giving Call Direct more time than necessary. If a CSR was on a call when their shift ended, they had to finish the call first. This often led to shifts being extended by five or ten minutes, sometimes longer. Late shifts (2.30-11pm) were no exception and some CSRs would be held back so late that anyone who used the 
bus to travel to and from work could miss the last bus home. Despite this, managers refused to allow employees to take back time and leave early on their next shift. It was acceptable for a CSR to work more than $7 \frac{1}{2}$ hours but unacceptable to work less. Given this inflexible attitude, many CSRs saw 'readyrelease' as a way of leaving on time.

Management referred to 'ready-release' as 'call avoidance', an employee refusing to do their job. Soon after 'going live' (leaving training) Ollie received a written warning from his team leader for call avoidance; he repeatedly 'ready-released' at the end of a shift and was caught. However, despite the risks, most informants knew about call avoidance. lan worked for Call Direct for 4 months and was never caught engaging in call avoidance:

"I was shown how to avoid calls by more experienced agents and other new recruits who were in the know. Because the statistics weren't monitored as much as they should've been, 'ready-release' was easy and would put me to the back of the queue. Loads of people did it and I was never caught doing it."

A management drive to scrutinise each CSR's statistics stopped many employees engaging in call avoidance, as Zoe explained:

Q - Were you aware of ways to cheat the system and avoid taking calls? A - For a little while, yeah. You could do 'ready-release' but they keep an eye on it now so you can't do it anymore.

Kim supported Zoe's claim that management had clamped down on call avoidance:

"Yeah, I did that for a little while but then they started doing print offs [of CSR's statistics] so they know when you've done one." 
As well as 'ready-release', Kim admitted to developing several methods to avoid calls during her 9 months at Call Direct. Her preference was 'dropping calls', releasing a call and hanging up on the customer:

$\mathrm{Q}$ - Did you drop many calls?

A - Yeah, all the time. Apart from that one time, they never followed up on it though. I could've ran a training course on dodging the system at that place! I learnt that as long as you kept saying 'hello' for 30 seconds or so after l'd released the call then if anyone was listening then it didn't look like I had dropped the call. Also, if I knew our manager hadn't got back off their break yet then l'd do it because there would be nobody supervising our team.

Q - Did someone show you how to make it look innocent or did you learn it yourself?

A - It was just something I picked up myself.

After receiving a written warning for dropping calls, Kim adapted her method so it no longer appeared deliberate. Rather than openly opposing the work process and the automated pace, Kim preferred to covertly drop calls and avoid talking to customers. Ready-release or call avoidance demonstrates the dichotomy between collective learning of techniques and the individualised implementation of such strategies. Call avoidance does not prevent in-flow of calls to the team, it prevents the individual employee handling a call; those calls will still be dealt with by other members of the team not engaged in call avoidance. Resistance strategies are not always and obviously collective despite a collective aspect of learning.

\section{Sabotage}

The final form of disobedience involved deliberately closing customers' accounts, particularly when a CSR knew they were going to be sacked. During the first 6 months with Call Direct, employees are on trial pending a probationary review designed to ascertain whether the CSR is hitting targets and performing highly enough to remain with the company. Any CSR who falls foul of the disciplinary 
process while still on probation can find their probationary review brought forward, usually indicating that they will be fired. However, Call Direct always scheduled the probationary review for the final hour of a shift, thus ensuring that each CSR worked a final 6 hours before being released.

During the participant observation, 4 CSRs on my team had their probationary review brought forward and each of them was 'released from their probation'. Given the certainty of dismissal, it was widely acknowledged that a CSR facing an early probationary review would spend their final shift arbitrarily closing customer accounts. Once an account was closed, it could not be automatically reactivated. If CSRs feel the company has no regard for them they are likely to feel disgruntled (Mulholland 2004). When CSRs knew they faced dismissal, their anger towards the company manifested itself as sabotage. The forms of resistance outlined previously correspond with Mars' (1982) concept of a 'donkey' fiddle; an employee who, constrained by the rules and controls of the workplace, resists through rulebreaking in a clear attempt to gain benefit from their employer. In the case of closing customer accounts and outright sabotage, the employee deviates from the 'donkey fiddle' as they are not looking for personal benefit or gain, merely to disrupt and inconvenience customers and the employer, a final gesture of contempt before being fired. As Mulholland (2004) noted, CSRs attempted to regain control by cutting corners, releasing calls, fiddling the system where possible, all in order to regain a measure of control. As my research indicates, when fiddling or resisting becomes ineffective, outright sabotage acted as the final gesture of revenge against an excessively controlling system of management.

\section{Trade Unions}

The notable absence in the forms of disobedience and resistance outlined above is the formal resistance of trade unionism, commensurate with the trend in declining union rights as well as individual employment rights since the early 1980s (Bagguley 2013). At Call Direct, trade union membership was not recognised although this was later relaxed and CSRs could bring union representation to performance review meetings with management, as was the case with Sarah who 
had required significant time off due to pregnancy. However, Sarah admitted that the thought of joining a union or bringing a representative did not cross her mind.

This attitude was rife amongst the employees at Call Direct, particularly the younger CSRs who have no frame of reference for the power of trade unions given the decimation of union strength before they were born. In the six months I spent at Call Direct, only one person spoke positively about the need for union representation. When asked about the potential support a trade union could provide, most employees shrugged it off. Zoe's response when asked about joining a trade union was representive,
“I'm not interested and I'm too lazy. Probably, I don't know the word to describe it...I don't care, I can't be bothered. That's me generally, l'll whinge and moan about something and try to do something but if I can't then that's about it."

Her attitude was clear and mirrored that of many of her co-workers: trade union involvement required time, effort, money and sacrifice, all things she was not prepared to give. It had not occurred to her that collective struggle may have more success than individual complaints and co-workers were not viewed as a potential source of collective strength. Throughout the research, co-workers and employees at Call Direct were clear about the problems they faced on a daily basis; an automated work process, targets, management pursuit of efficiency, dehumanising practices such as being denied permission to use the bathroom (Lloyd forthcoming), and the routine use of affective labour. They used informal techniques of disobedience, shared throughout the organisation, to push back against an acknowledged oppressive work process but it stopped there. This was not the basis for a future, more formal, collective resistance. My informants could not make the link between what they did to informally alleviate their daily indignities and a more formal organised attempt to change the conditions of their working existence. 
This raises implications for the concept of the collective worker. Mulholland (2004) presented similar findings in terms of the disconnect between informal and formal practices at PhoneCo but suggested that the recognition of the collective nature of their workplace oppression was a stepping stone towards something more formal and organised in the future. In the next section, a deeper discussion of ideology will suggest that the underlying assumptions held in the concept of the collective worker create problems in the actualisation of that leap from informal to formal resistance.

\section{Ideology}

Marxist scholars suggest ideology works at the level of false consciousness (Eagleton 2007). Ideology works as an illusory representation of reality, masking the true nature of reality in an illusion located in knowledge (ibid); once we become cognisant of the illusion, the veil of false consciousness falls and we attempt to change our material conditions. Of course, this signals the basis for the proletarian revolution (Marx \& Engels 1998). LPT follows this line of ideological thinking. Informal acts of disobedience and resistance to the work process, shared amongst co-workers, indicate their collective exploitation and form the basis for potential co-ordinated resistance. The data presented here from Call Direct could also be interpreted in this way; the informal acts of disobedience against the work process demonstrate the existence of a 'collective worker' that suggests an optimistic hope for future struggle.

However, for the purposes of a more dialectical discussion, allow us to consider the data presented above in light of an alternative interpretation of ideology (Zizek 1989; 2010). For Zizek, ideology is an unconscious fantasy structuring our social reality. That fantasy is the libidinal drive encouraged and structured by consumer capitalism; our desire for commodities and objects provides the energy that fuels the system (Zizek 1989; Hall 2012). The function of ideology is 'not to offer us a point of escape from our reality but to offer us the social reality itself as an escape from some traumatic, real kernel' (Zizek 1989: 45). The illusion, the fantasy, takes place at the point of action as opposed to knowing; the illusion structures our social reality, our social relations and we believe we know how 
things really are but act as though we do not know. Today, ideology is not taken seriously and people no longer believe in ideological positions; postmodernism has fractured the notion of a universal truth or attachment to ideology (Zizek 1989). We are too knowing to be duped by ideology. Instead, we engage in a 'fetishistic disavowal', maintaining an ironic detachment or cynical distance (Fisher 2009) from 'reality'. Ironic or cynical distance serves to perpetuate the prevailing ideological edifice (Zizek 1989).

Capitalism structures our social relations and social reality and whilst we believe that we know about its exploitative conditions and oppressive practices, we wilfully participate as if we did not know these things. Thus, for Zizek, ideology works at the point of acting. We see this in the rejection of brand values at Call Direct; employees, at the point of knowing, actively resist whilst, at the point of acting, continue the relatively smooth functioning of the work process that continues to create surplus value for the company.

Capitalism endures because it 'allows' resistance to take place. As a fluid system, capitalism requires libidinal energy to sustain itself (Hall 2012); desire and drive fuelled by consumer culture. The expenditure of this energy ensures capitalism continues. As a system organising social relations, capitalism is elastic enough to entertain criticism and disillusionment without being truly threatened (Hall et al 2008). Boltanski and Chiapello (2005) note that the 1960s criticism of capitalism as alienating, particularly in the workplace, was appropriated by capitalism and engendered a 'new spirit' which became contemporary, flexible, network capitalism. Any real threat to capitalism's existence is cut off and the system adapts to survive. However, Sloterdijk (2010) suggests that individuals possess thymotic as well as libidinal energy; rage, recognition, pride and dignity produce a different type of energy that has a potentially collective element. Channelled appropriately and through formal functioning institutions or symbolic structures, this rage constitutes revolutionary potential.

In the workplace, rage manifests itself in the search for dignity and recognition denied by a work process that treats individuals as interchangeable parts to be 
replaced upon burn out. A target-driven management culture that builds burnout and turnover into its HR strategy (Wallace et al 2000) generates resistance and unrest amongst employees. However, without a symbolic order (Zizek 2010) to channel that rage towards, nothing changes. By maintaining a cynical distance from the conditions of the workplace, rejecting brand values and ensuring coworkers know how to claw back seconds from the automated work process, rage dissipates (Sloterdijk 2010). The individual feels they have registered their disgust at an oppressive work process by taking back time, dropping calls or rejecting brand values. This resentful energy is banked by the capitalist system; capitalism in its consumer phase channels the pent up energy and aggression dissipating in the workplace and offers us a conciliatory outlet (Hall et al 2008). Consumer culture offers immediate gratification and compensation for the drudgeries of work(Lloyd 2013). Sloterdijk (2010: 64) suggests that 'vengeful acts of expression mean nothing more than a narcissistic expenditure of energy'; rage against injustice or recognition in the workplace is an isolated waste of energy that only serves to breathe new life into a system that has factored in individualised resistance. That energy is used as fuel to sustain the existing social relations projected by capitalism whilst the individual continues to participate in an oppressive, exploitative work process ameliorated by the belief that their 'knowingness' or cynicism inures them from the iniquities of their existence.

\section{Conclusion}

It is clear from the data presented above that there is disobedience, misbehaviour and resistance occurring in the workplace, as it has done throughout the entirety of sociological analyses of working life. In many ways, the disobedience demonstrated at Call Direct is a continuation of the practices embodied in industrial labour (Beynon 1975; Braverman 1974). LPT attempts to reconnect resistance with the work process in the hope of identifying avenues for change in the relationship between capital and labour, employer and employee but is ultimately misguided in its theoretical framework.

This paper argues that the empirical evidence presented above has different implications depending on the interpretation of ideology applied to the data. This 
paper has asked sociology to consider the implications of rethinking ideology and its impact on individuals and workplaces. In order for sociology as a discipline to move beyond staid debates, theoretical cul-de-sacs and false optimism, new ideas that connect the particular of micro-sites such as the call centre with the universal of ideology, neoliberalism and market capitalism are essential. The aim here is to ask sociologists of the workplace to engage with an alternative conception of ideology that may go some way towards explaining why, in particular settings resistance appears alive and well but, at a universal level, nothing actually changes, capitalism endures whilst allowing the subject to think they have 'got one over' on their employer and oppressive work processes that, despite their disobedience and misbehaviour, remain intact.

\section{Bibliography}

Ackroyd, S. and Thompson, P. (1999) Organizational Misbehaviour. London: Sage. Bagguley, P. (2013) “Industrial Citizenship: A re-conceptualisation and case study of the UK" in International Journal of Sociology and Social Policy. 33(5/6) 265-279. Bain, P. and Taylor, P. (2000) “Entrapped by the 'electronic panoptican'? Worker resistance in the call centre" in New Technology, Work and Employment. 15(1) 218.

Baudrillard, J. (2007) Forget Foucault. Los Angeles: Semiotext(e).

Beck, U. and Beck-Gernsheim, E. (2002) Individualization. London: Sage.

Beynon, H. (1975) Working for Ford. London: Penguin.

Blauner, P. (1964) Alienation and Freedom: The Factory Worker and his Industry. London: University of Chicago Press.

Boltanski, L. and Chiapello, E. (2005) The New Spirit of Capitalism. London: Verso. Bond, S. (2004) "Organisational culture and work-life conflict in the UK" in International Journal of Sociology and Social Policy. 24(12) 1-24.

Braverman, H. (1974) Labor Monopoly and Capital: The Degradation of Work in the Twentieth Century. New York; Monthly Review Press.

Brophy, E. (2010) “The subterranean stream: Communicative capitalism and call centre labour" in Ephemera: Theory and Politics in Organization. 10(3/4) 470-483. Brown, A. (1998) Organisational Culture. (2 ${ }^{\text {nd }}$ Ed.) London: Prentice Hall. Bryman, A. (2012) Social Research Methods. (4 ${ }^{\text {th }}$ Ed.) Oxford: University Press. 
Burawoy, M. (1979) Manufacturing Consent: Changes in the labor process under monopoly capitalism. Chicago: University Press.

Burnett, S.A. and Huisman, J. (2010) “Universities' responses to globalisation: The influence of organisational culture" in Journal of Studies in International Education. 14(2) 117-142.

Deery, S., Iverson, R. and Walsh, J. (2002) "Work relationships in telephone call centres: understanding emotional exhaustion and employee withdrawal" in Journal of Management Studies. 39(4) 471 - 496.

Duncan, M. (2004) "Autoethnography: Critical appreciation of an emerging art" in International Journal of Qualitative Methods. 3(4) 28-39.

Dworkin, D. (1997) Cultural Marxism in Post-War Britain. Durham, NC: Duke University Press.

Eagleton, T. (2007) Ideology: An Introduction. (2 $\left.{ }^{\text {nd }} E d.\right)$ London: Verso.

Edwards, P.K. (1990) "Understanding Conflict in the Labour Process: The Logic and Autonomy of Struggle" in Knights, D. and Willmott, H. (Eds.) Labour Process Theory. London: Macmillan.

Fisher, M. (2009) Capitalist Realism. Winchester: Zero Books.

Fleming, P. and Sturdy, A. (2011) “'Being yourself' in the electronic sweatshop: New forms of normative control” in Human Relations. 64(2) 177-200.

Glucksmann, M. (2004) "Call configurations: Varieties of call centre and divisions of labour" in Work, Employment and Society. 18(4) 795-811.

Hall, S., Winlow, S. and Ancrum, C. (2008) Criminal Identities and Consumer Culture: Crime, Exclusion and the New Culture of Narcissism. London: Willan.

Hall, S. (2012) Theorizing Crime and Deviance: A New Perspective. London: Sage.

Knights, D. (1990) "Subjectivity, Power, and the Labour Process" in Knights, D. and Willmott, H. (Eds.) Labour Process Theory. London: Macmillan.

Knights, D. and Willmott, H. (1989) "Power and Subjectivity at Work: From Degradation to Subjugation in Social Relations" in Sociology. 23(4) 535-558.

Lacan, J. (2007) Ecrits. London: W.W. Norton \& Company.

Lloyd, A. (2012) "Working to live, not living to work: Work, leisure and youth identity among call centre workers in North East England" in Current Sociology. 60(5) 619-635. 
Lloyd, A. (2013) Labour Markets and Identity on the Post-Industrial Assembly Line. Farnham: Ashgate.

Lloyd, A. (2016) "Understanding the Post-Industrial Assembly Line: A Critical Appraisal of the Call Centre" in Sociology Compass. 10(4) 284-293 doi: $10.1111 /$ soc 4.12360 .

Lloyd, A. (forthcoming) "Efficiency, Productivity and the Comfort Break: The gap between ideological rhetoric and reality in the call centre".

Mars, G. (1982) Cheats at Work: An Anthropology of Workplace Crime. London: Unwin Paperbacks.

Martinez Lucio, M. and Stewart, P. (1997) "The Paradox of Contemporary Labour Process Theory: The Rediscovery of Labour and Disappearance of Collectivism" in Capital and Class. 62. 49-77.

Marx, K. and Engels, F. (1998) The Communist Manifesto. Oxford: University Press. McCabe, D. (2007) "Individualization at Work?: Subjectivity, Teamworking and Anti-Unionism" in Organization. 14(2) 243-266.

McFadden, P. (2015) "The Production of Politics in Front-Line Service Work: 'Body Work' in the Labour Process of the Call Centre Worker" in Global Society. 29(1) 89106.

Mulholland, K. (2004) 'Workplace resistance in an Irish call centre: slammin', scammin', smokin', and leavin'" in Work, Employment and Society. 18(4) 709-724.

O'Doherty, D. and Willmott, H. (2001) “Debating Labour Process Theory: The Issue of Subjectivity and the Relevance of Poststructuralism" in Sociology. 35(2) 457476.

Parker, R. and Bradley, L. (2000) "Organisational culture in the public sector: Evidence from six organisations" in International Journal of Public Sector Management. 13(2) 125-141.

Robinson, G. and Morley, C. (2006) "Call centre management: Responsibilities and performance" in International Journal of Service Industry Management. 17(3) 284300.

Savage, M. et al. (2015) Social Class in the $21^{\text {st }}$ Century. UK: Pelican.

Sloterdijk, P. (2010) Rage and Time: A Psychopolitical Investigation. New York: Columbia University Press. 
Spencer, D.A. (2000) "Braverman and the Contribution of Labour Process Analysis to the Critique of Capitalist Production - Twenty-Five Years On" in Work, Employment and Society. 14(2) 223-243.

Spicker, P. (2011) "Ethical covert research" in Sociology. 45(1) 118-133.

Strangleman, T. (2005) "Sociological Futures and the Sociology of Work" in Sociological Research Online. 10(4).

Taylor, P. and Bain, P. (1999) “'An assembly line in the head': work and employee relations in the call centre" in Industrial Relations Journal. 30(2) 101-117.

Thompson, P. (1990) "Crawling from the Wreckage: The Labour Process and the Politics of Production" in Knights, D. and Willmott, H. (Eds.) Labour Process Theory. London: Macmillan.

Thompson, P. (2003) "Fantasy Island: a Labour Process critique of the "age of surveillance"” in Surveillance and Society. 1(2) 138-151.

Thompson, P. and Smith, C. (2009) "Labour Power and Labour Process: Contesting the Marginality of the Sociology of Work" in Sociology. 43(5) 913-930.

Tinker, T. (2002) "Spectres of Marx and Braverman in the twilight of postmodernist labour process research" in Work, Employment and Society. 16(2) 251-281.

Van Amstel, H. (2013) "The ethics and arguments surrounding covert research" in Social Cosmos. 4(1) 21-26.

Van den Broek, D. (2004) “'We have the values': Customers, control and corporate ideology in call centre operations" New Technology, Work and Employment. 19(1) 2-13.

Wallace, C.M., Eagleson, G. and Waldersee, R. (2000) "The sacrificial HR strategy in call centers" in International Journal of Service Industry Management. 11(2) 174-184.

Willmott, H. (1990) "Subjectivity and the Dialectics of Praxis: Opening up the Core of Labor Process Analysis" in Knights, D. and Willmott, H. (Eds.) Labour Process Theory. London: Macmillan.

Winlow, S. and Hall, S. (2006) Violent Night: Urban Leisure and Contemporary Culture. Oxford: Berg.

Winlow, S. and Hall, S. (2013) Rethinking Social Exclusion: The End of the Social? London: Sage. 
Winlow, S., Hall, S., Treadwell, J. and Briggs, D. (2015) Riots and Political Protest: Notes from the Post-Political Present. London: Routledge.

Woodcock, G. (1944) 'The Tyranny of the Clock' in War Commentary - For Anarchism. Available at www.acsu.buffalo.edu/ rrojas/TyrannyofClock.html (Accessed: 16/10/2013).

Zamora, D. (2015) Foucault and Neoliberalism. Cambridge: Polity Press.

Zizek, S. (1989) The Sublime Object of Ideology. London: Verso.

Zizek, S. (2000) The Ticklish Subject: The Absent Centre of Political Ontology. London: Verso.

Zizek, S. (2010) Living in the End Times. London: Verso. 